\title{
Peculiarities of the high-dividend strategies in the markets of developed and developing countries
}

\author{
Maria Melnikova ${ }^{1, *}$, Elizaveta Markovskaya ${ }^{2}$, Peter Kukhtin $^{3}$, and Peter Grabovyy ${ }^{4}$ \\ ${ }^{1}$ Saint Petersburg State University,13B, Universitetskaya Emb., 199034, St. Petersburg, Russia \\ ${ }^{2}$ National Research University Higher School of Economics, 16, Souyza Pechatnikov str., 190008, \\ Saint Petersburg, Russia \\ ${ }^{3}$ Financial University under the Government of the Russian Federation, Leningradsky,49,125993, \\ Moscow, Russia \\ ${ }^{4}$ Moscow State University of Civil Engineering, 26 Yaroslavskoye Shosse, 109377, Moscow, Russia
}

\begin{abstract}
The purpose of the study is to analyze the features of highly dividend strategies in the markets of developed and developing countries. For the analysis of dividend strategies, two developing countries and two developed were chosen to analyze the practical significance of dividend strategies in different markets. In addition to practical interest, this work is relevant in that there are a number of studies on individual countries, but there is no similar data for pooled data on developed or emerging markets. The paper considers the markets of such countries as Russia, India, Spain, Japan. The study consists of two main blocks: testing the hypothesis on each market in the country separately and assessing the effectiveness of various modifications of dividend strategies on the combined data separately for developed and developing countries. The results of this work can be used as a recommendation on investment in the considered markets, as well as for further studies of excess return on dividend strategies.
\end{abstract}

\section{Introduction}

The classic investment strategy, Dogs of the Dow (Dow-10), was firstly mentioned in 1988 by John Slater, analyst, in his material published in the Wall Street Journal. He examined 10 shares of the Dow Jones index and found out that the return on investments in stocks with high dividends exceeds the return on index over the time period since 1973 till 1988. A number of researchers wrote about the advantages of this strategy $[1,2]$.

The most important academic study of the Dogs of the Dow strategy was done in 1997 [3]. The authors used statistical methods to study the performance of a portfolio for 50 years, from 1946 to 1995 . The researchers concluded that such a strategy had statistically outperformed the Dow index, but not economically, if risk, tax, and transaction costs are

\footnotetext{
* Corresponding author: angela-1309.m@yandex.ru
} 
being adjusted as rebalancing costs.

As from the introduction of the Dogs of the Dow strategy into the investment world of John Slater (1988), it remains one of the most discussed and studied topics in foreign capital markets, since it is suitable not for every single market. Cordeiro in his analytical article (2006) says that the Dogs of the Dow show excess returns on the US capital market; Morgan and Thomas (1998) showed that dividend strategies also have positive riskadjusted results in the UK; Visscher and Filbeck (1997) found out that the Dogs of the Dow strategy beats the market for only 4 years out of 14 years, both before and after the risk adjustment, as compared with the FTSE100 index. However, when Gwilymet al. (2005) selected the FT30 index shares for analysis, the dividend strategy had showed an excellent profitability against the market on average from 1980 to 2001 , even after the adjusting against the transaction costs [4-8].

On the Australian market, from 2000 to 2006, the Alles and Shen's (2008) Dogs of the Dow strategy had also beat the market; Visscher and Filbeck (2003) have confirmed the Dogs of the Dow strategy effectiveness on the Canadian stock market. Brzeszczynski and Gajdka (2008) concluded that the Dogs of the Dow strategy was outpacing the WIG index in Poland from 1997 to 2007, and later the Eemeli and Sami (2011) had made a similar conclusion with respect to the Finnish stock market. In 2013, Qiuetal. had published successful results of the Dogs of the Dow strategy with regard to the Japanese market. Wangetal. (2011) found that portfolios modelled on the Dogs of the Dow strategy have significantly outpaced the market performance even after the adjusting of transaction costs and tax accounting for the period from 1994 to 2009 on the Chinese market. By using data from 1992 to 2007, ChongandLuk (2010) had explained the reason why dividend strategies work best for blue-chip stocks in Hong Kong. DaSilva (2001) had concluded that most of the evidence confirms that the Dogs of the Dow strategy outperforms all the Latin American markets except for Brazil, but the results were not statistically significant [9-15].

However, various studies have shown the negative effectiveness of the Dogsof the Dow strategy [16-25].

Along with the classic Dogsof the Dow strategy, its modifications are arising, which are analyzed against the excess returns in relation to the various countries market.

K.E. Kuzmichev (2012) in his paperon the Russian stock market from 2003 to 2010 analyzes the effectiveness of Top 1, Top 2, The High Yield 5 and DoD strategies with respect to MICEX index. With no taking risk and transaction costsinto account, the strategies show the excess returns, which remain only in the classical version of the strategy after all the necessary [26].

In the Asian markets, the results obtained were different than for the Russian market: a portfolio of 10 high-yielding stocks can receive negative returns annually against a portfolio of 5 high-yielding stocks in Hong Kong market; portfolios with 5 high-dividend stocks are preferable in terms of profitability and risk [27,28].

One of the well-known modifications was proposed by O'Higgins and Downes (1991). For its implementation, 5 out of 10 shares of companies featuring the highest dividend yield are used, however, the choice is made by the lowest market value of the shares [29].

Another newly proposed in 1996 strategy is The Foolish Four. A basis for the method of this strategy development is the strategy of Beating the Dow 5 and it excludes a share with the lowest price out of it.

A separate family of modified strategies are the Reverse Procedure strategies. All variations of the Reverse Procedure strategy exclude the first share, so the Reverse Procedure 4 strategies will include 2, 3, 4 and 5 shares [30].

There is also a number of other Dogs of the Dow strategies, e.g. according toWolmarans study (2004), such modifications were advantageous in the South African market for 25 years [31]. 


\section{Research methodology}

\subsection{Description of main stages of study}

The study consists of two main blocks: testing of the established hypothesis in each country market separately and evaluating of the effectiveness of various modifications of dividend strategies on pooled data separately by developed and developing countries.

The purpose of the first block is to analyze the effectiveness of a high-dividend strategy on a specific market in question for the covered period. December is considered a standard month for returns calculation and portfolio rebalancing, but actually the re-development could be done from the end of July, when most companies will have paid dividends for the previous period; thus, the study will identify the baseline month featuring the highest average yield. In order to be able to compare the obtained results, the same portfolio modeling strategies will be applied for all countries, and the portfolio adjustment will be done once a year. The sample will include stocks of companies included in the structure of stock index of each country, and the index itself will act as a benchmark in the study. Criteria for the results analyzing are as follows:

1. Do dividend strategies feature excess returns versus the index.

2. Does a high-dividend portfolio yield a more profit than an investing in a portfolio with low dividends.

3. Will the calculated baseline month be different in average yield against the standard baseline month (December).

4. Will the high-dividend portfolios feature higher Sharpe andSortino ratios and a modified Sharpe ratio.

In the second block, the modifications are tested and their effectiveness is compared over the combined data by the developed sector (Spain, Japan) and the developing sector (Russia, India).

In the first part of the study, the stocks of companies will be sorted by dividend yield in each year, and thentwo types of portfolios based on the calculated indicators will be formed: high-dividend and low-dividend portfolios. The gradation by portfolios will be made by ranked dividend yield in the ratio of $50 \%$ to $50 \%$; the shares with zero dividends will be included in low-dividend portfolios. Since the number of shares in a portfolio depends on the number of issuers of shares in a country index, it will change over the covered period. In order to identify the basline month, there will also be portfolios formed according to the classic Dogs of the Dow (HighYield 10), High Yield 5 and High Yield 1 strategy. In most cases, the month featuring the highest average yield coincides for all five represented portfolios, as well as for the index; in cases when the month featuring the highest average yield does not match among the portfolios, either the month that has predominantly showed the highest yield among the portfolios, or the classic baseline month (December) will be chosen. Further, five equally weighted portfolios are formed - there is an inclusion of shares with equal weights in the portfolio, where the weight of the share is calculated as follows:

$$
W_{i}=\frac{1}{n}
$$

where $W_{i}$ is the weight of $i$ share and $n$ is the total number of shares in the portfolio.

In order to calculate the number of securities for each share, the amount to be invested in this share should be divided by the share price. The weight of a share in a portfolio weighted by capitalization is calculated in a similar manner; it is equal to the ratio of the market capitalization of a share to the market capitalization of all shares in the portfolio, where market capitalization is the product of the number of shares and their market price: 


$$
W_{i}=\frac{Q_{i} P_{i}}{\sum_{j=1}^{n} Q_{j} P_{j}}
$$

where $W_{i}$ is the weight of $i$ share, $Q_{i}$ is the number of $i$ shares, $P_{i}$ is the price of $i$ offerand $n$ is the number of shares in the portfolio.

Within the framework of this study, the test of the hypothesis that a weighted portfolio of capitalization gives the lowest yield in comparison with a portfolio with equal weights will not be carried out; all the portfolios will initially be formed as equally weighted according to paper of M.A. Galperina and T.V. Teplova [32].

This study implies that portfolio rebalancing occurs once every 12 months, which corresponds to the classical variant for all 13 years. The beginning of the investment period falls on the second half of a calendar year, since by July the majority of issuing companies had already decided on the size of dividends, which allows for accurate calculations of dividend yields. Thus, five equally weighted portfolios will be annually tested from July to December in order to identify the month featuring the highest average yield, and it will be the baseline one.

The formation of an equally weighted portfolio will be carried out in accordance with the method proposed in the paper of M.A. Galperina and T.V. Teplova [32]. In each year, the initial capital for the formation of a portfolio is equal to USD 100 thousand, and depending on the number of selected companies, the amount is distributed between them equally. The number of shares of each company is calculated by dividing the amount by the market value of a share at the time of the portfolio forming. After 12 months, the returns obtained due to a change of the market value of the shares are calculated; dividends are not taken into the calculation of returns, and are not capitalized for the following investment periods. Also, the portfolio is reformed with the updated data by dividend profitability of companies. The same method will be used to compile a portfolio weighted by capitalization. The only difference is in the distribution of USD 100,000, it is carried out according to the calculated weight of each company [32].

In order to do the risk adjustment, the Sharpe and Sortino ratio and the modified Sharpe ratio will be applied as described in the paper of N.I. Berzon and D.I. Doroshin [33].

The Sharpe ratio aims to measure the desirability of investments by dividing the difference in average return over a period and the risk-free rate by the standard deviation of return.

$$
\text { Sharpe Ratio }=\frac{E\left[R p-R_{f}\right]}{\sigma}=\frac{E\left[R p-R_{f}\right]}{\sqrt{\operatorname{Var}\left[R-R_{f}\right]}}
$$

where $R p$ is the expected return on the portfolio for the period, $R_{f}$ is the risk-free rate, and $\sigma$ is the standard deviation of return.

The Sortino ratio is a metric that is a modification of the Sharpe ratio with the use of not a two-sided standard deviation, but only a one-sided standard deviation, including the potential loss of the asset. The ratio is calculated by the following formula:

$$
\text { Sortino Ratio }=\frac{R p-M A R}{\sigma_{p}^{n}}
$$

where $M A R$ is the minimum allowed level of profitability, it is often equal to the risk-free rate, and $\sigma_{p}^{n}$ is one-sided standard deviation calculated by the following formula:

$$
\sigma_{p}^{n}=\sqrt{\frac{\sum_{t=1}^{T} \min \left(R_{p, t}-M A R\right)^{2}}{T}}
$$

where $T$ is the time period and $R_{p, t}$ is the portfolio $p$ yield for the time period $t$. 
Despite the advantages of this ratio, it is criticized. The ratio is not stable over time and does not take into account the asymmetry of the data.

The third selected ratio most correctly assesses the risk of assets, since it solves the problem of distribution abnormalities through the considering of excess and asymmetry in the calculation. A modified Sharpe ratio was proposed in Favre and Galeano (2002) paper with the following calculation methodology [34]:

$$
\text { Modified Sharpe Ratio }=\operatorname{ShR} *\left(1+\left(\frac{A}{6}\right) * \operatorname{Sh} R-\left(\frac{E}{24}\right) * \operatorname{ShR}^{2}\right)
$$

where $S h R$ is the value of the Sharpe ratio, $A$ is the value of the portfolio asymmetry and $E$ is the value of the portfolio excess.

In this paper asymmetry will be calculated as follows:

$$
A=\frac{\sum_{i=1}^{n}\left(r_{i}-\bar{r}\right)^{3}}{n \sigma^{3}}
$$

where $r_{i}$ is the portfolio yield at time $i, \bar{r}$ is the average portfolio yield for the considered period, and $n$ is the number of assets in the portfolio.

A positive asymmetry value means that a higher return is more likely to be, while a negative asymmetry indicator implies the greatest likelihood of a low return.

The excess ratio makes sense when comparing two or more assets that are symmetrically equally distributed. Assets featuring the lowest rate of excess are considered as more risky ones. The excess is calculated by the following formula:

$$
E=\frac{\sum_{i=1}^{n}\left(r_{i}-\bar{r}\right)^{4}}{n \sigma^{4}}-3
$$

In order to test the sensitivity of the high-dividend portfolio to market risk, the capital asset pricing model (CAPM) developed by Sharp and Lintner and the Fama-French threefactor model will be used.

The CAPM model measures risk and the relationship between expected return and risk. This model is as follows:

$$
R_{p}-R_{f}=\alpha_{p}+\beta_{p} *\left(R_{m}-R_{f}\right)
$$

where $R_{m}$ is the yield of the market portfolio, $\alpha_{p}$ is the ratioevaluating excess returns to the market, and $\beta_{p}$ (beta portfolio) is the ratio of the portfolio showing the effect of systematic risk on returns.

The Fama-French three-factor model is determined by three factors: the excess profit of a broad market portfolio, the difference between the yield of a portfolio with shares of small and large-cap companies, and the difference between the yield of a portfolio with a high book value multiplier and a low one.

The following model option will be used in the calculations:

$$
R_{p}-R_{f}=\alpha_{p}+\beta_{p} *\left(R_{m}-R_{f}\right)+\beta_{S M B} * S M B+\beta_{H M L} * H M L+\varepsilon_{p}
$$

The first part of the model is similar to the CAPM model, although the results will not be the same; the SMB (small minus big) indicator characterizes the profitability of the portfolio by company size, and the HML (high minus low) indicator characterizes the profitability of the portfolio by value (the MV/BV multiplier will be used). The beta ratios for SML and HML measure these indicators sensitivity to risk.

The SMB and HML indicators will be calculated independently based on a database from the Thomas Reuters Eikon terminal with a simplification of the classical Fama-French 
approach. For the first indicator, the shares will be sorted by market capitalization for the year from the lowest to the highest, and for the second one, by the multiplier from the highest to the lowest. After ranking, the shares are divided into two equal groups. In order to calculate the SMB, the yield of $50 \%$ of the stocks with the largest market capitalization will be deducted from the yield of $50 \%$ of the stocks with the smallest market capitalization. A similar procedure will be performed to calculate the HML. The difference against the classical approach is that for the SMB indicator, two portfolios are formed instead of three, and when SMB and HML portfolios are being formed, the ratios are cleared from each other's influence. In this paper, there is no such an adjustment; accordingly, the correlation between the factors will be calculated, and if it will not be that high, the multicollinearity problem can be deemed solved.

In the second part of the study, portfolios of modified strategies will be modeled based on the aggregated data separately for the developed and the developing countries. All portfolios are assumed to be equally weighted, and December is chosen as the baseline month. The modifications that will be used for the returns benchmarking are listed in Table 1 below:

Table 1. Modifications of the dividend strategy.

\begin{tabular}{|c|l|}
\hline High Yield 10 (HY10) & 10 equities with highest dividend return \\
\hline High Yield 5 (HY5) & 5 equities with highest dividend return \\
\hline High Yield 1 (HY1) & 1 equity with highest dividend return \\
\hline Beating the Dow (BTD) & 5 equities with smallest prices from HighYield 10 \\
\hline Penultimate profit prospect (PPP) & 2 equities with smallest prices from HighYield 10 \\
\hline Foolish Four (FF) & $\begin{array}{l}\text { Equities from BeatingtheDow without equities } \\
\text { with smallest price }\end{array}$ \\
\hline Foolish Two (FT) & 1,2 equities from Foolish Four \\
\hline
\end{tabular}

\subsection{Sample description}

The basic data for the study are the major indices of countries with the developed trading platforms which correspond to the selected study period: 2004-2017, where 2004 will be the first year of portfolio formation based on dividends paid for 2003 and market value of shares as for 2004. The countries which indices were not calculated for the covered period, as well as the countries having no full list of the constituent companies were excludedfrom the formed list; then two countries with developed economies and two with developing ones were randomly selected. Russia is in the list of developing countries.

The final list of countries and their respective indices is presented below:

1. Spain (IbeX35 Index)

2. Japan (TOPIX Index)

3. Russia (MICEX Index)

4. India (BSESensex 30 Index)

For each country, monthly share quotes, annual dividend values, annual capitalization of companies, and annual P/B ratios were collected. Initially, the data were downloaded in national currency; therefore, in order to compare the results in the future adequately, all the values were converted into US dollars according to the exchange rate of each year. Due to the conversion into dollars, the yield of 10-year US Treasury bonds will be taken as a riskfree rate.

When calculating the portfolio returns, dividend payments will not be capitalized, since the indices do not include them into their value; the total dividend payments were also taken into account, that is, semi-annual dividends are not used in the analysis separately.

The Thomas Reuters Eikon terminal was used as the database. 


\section{Results and discussion}

\subsection{Formation of high-dividend portfolios in the russian market}

In the Russian market, 80 companies included in theMOEX 5 index from July 30, 2003 to December 2016 were used in the study. The benchmark is the MICEX index, which currently includes 50 companies and is revised once a quarter.

The shares were sorted and the following portfolios were formed by dividend yield in 2003: low-dividend, high-dividend, Top 1, Top 5 and Top 10; respectively, the year 2004 will be the first year of the portfolio work. After analyzing the profitability by months (July to December) for 13 years, it was found that the preferred month of portfolio rebalancing for high-dividend strategies is December, so it will be the baseline month in this country in the future. The results of portfolio returns are presented in Table 2 below.

Table 2. The profitability of portfolios and the MICEX index in 2004-2017 (Source: Authors' calculations).

\begin{tabular}{|c|c|c|c|c|c|c|}
\hline & $\mathbf{1 0}$ & $\mathbf{5}$ & $\mathbf{1}$ & $\begin{array}{c}\text { High dividend } \\
\text { portfolio }\end{array}$ & $\begin{array}{c}\text { Low dividend } \\
\text { portfolio }\end{array}$ & $\begin{array}{c}\text { Moscow } \\
\text { Currency } \\
\text { Exchange }\end{array}$ \\
\hline 2004 & $33.75 \%$ & $61.44 \%$ & $5.92 \%$ & $61.44 \%$ & $5.13 \%$ & $13.25 \%$ \\
\hline 2005 & $88.06 \%$ & $113.20 \%$ & $192.42 \%$ & $113.20 \%$ & $58.85 \%$ & $76.49 \%$ \\
\hline 2006 & $73.59 \%$ & $82.68 \%$ & $21.55 \%$ & $71.35 \%$ & $82.49 \%$ & $82.43 \%$ \\
\hline 2007 & $27.28 \%$ & $23.97 \%$ & $36.93 \%$ & $27.28 \%$ & $23.36 \%$ & $19.78 \%$ \\
\hline 2008 & $-72.35 \%$ & $-76.95 \%$ & $-67.22 \%$ & $-75.35 \%$ & $-78.23 \%$ & $-73.65 \%$ \\
\hline 2009 & $224.54 \%$ & $278.05 \%$ & $247.90 \%$ & $229.10 \%$ & $135.42 \%$ & $123.17 \%$ \\
\hline 2010 & $32.43 \%$ & $24.09 \%$ & $6.66 \%$ & $37.72 \%$ & $243.19 \%$ & $22.09 \%$ \\
\hline 2011 & $-22.39 \%$ & $-14.68 \%$ & $-0.90 \%$ & $-25.10 \%$ & $-34.00 \%$ & $-21.25 \%$ \\
\hline 2012 & $10.66 \%$ & $7.96 \%$ & $41.66 \%$ & $8.08 \%$ & $-3.27 \%$ & $10.94 \%$ \\
\hline 2013 & $-4.03 \%$ & $-18.23 \%$ & $20.68 \%$ & $-5.91 \%$ & $-13.19 \%$ & $-5.18 \%$ \\
\hline 2014 & $-44.42 \%$ & $-28.61 \%$ & $-76.57 \%$ & $-42.86 \%$ & $-53.43 \%$ & $-47.46 \%$ \\
\hline 2015 & $20.47 \%$ & $36.50 \%$ & $48.16 \%$ & $20.12 \%$ & $7.51 \%$ & $0.45 \%$ \\
\hline 2016 & $46.00 \%$ & $44.05 \%$ & $71.71 \%$ & $41.52 \%$ & $84.89 \%$ & $50.82 \%$ \\
\hline \multicolumn{1}{|c|}{2017} & $7.82 \%$ & $6.46 \%$ & $-6.63 \%$ & $1.84 \%$ & $7.15 \%$ & $0.53 \%$ \\
\hline $\begin{array}{l}\text { Average } \\
\text { annual } \\
\text { return }\end{array}$ & $30.10 \%$ & $38.57 \%$ & $38.73 \%$ & $33.03 \%$ & $33.28 \%$ & $18.03 \%$ \\
\hline $\begin{array}{l}\text { Sharp } \\
\text { ratio }\end{array}$ & 0.428 & 0.459 & 0.443 & 0.446 & 0.399 & 0.347 \\
\hline $\begin{array}{l}\text { Sortino } \\
\text { ratio }\end{array}$ & 1.084 & 1.462 & 1.246 & 1.054 & 1.052 & 0.585 \\
\hline $\begin{array}{l}\text { Modified } \\
\text { Sharp } \\
\text { Ratio }\end{array}$ & 0.461 & 0.503 & 0.479 & 0.479 & 0.427 & 0.353 \\
\hline $\begin{array}{l}\text { Standart } \\
\text { deviation }\end{array}$ & 0.703 & 0.840 & 0.875 & 0.741 & 1.983 & 0.239 \\
\hline Excess & 4.142 & 4.867 & 1.985 & 3.082 & 1.243 & 0.337 \\
\hline Assymetry & 1.533 & 1.817 & 1.323 & 1.348 & & \\
\hline
\end{tabular}

The average annual yield of the high-dividend portfolio and the Top 10 portfolio almost twice outperformed the market portfolio, while the Top 1 and Top 5 portfolios beat the index more than twice. The low-dividend portfolio also over performed the MICEX index and beat the high-dividend portfolio in the period under study, which can be explained by growth of shares and high yields in 2009 and 2010. The highest volatility in the calculations 
of the portfolio formed by the Top 1 strategy, which is not surprising, since the portfolio was formed out of one company shares for one year. Figure 1 clearly shows that a highdividend portfolio nearly always exceeds the benchmark for 13 years.

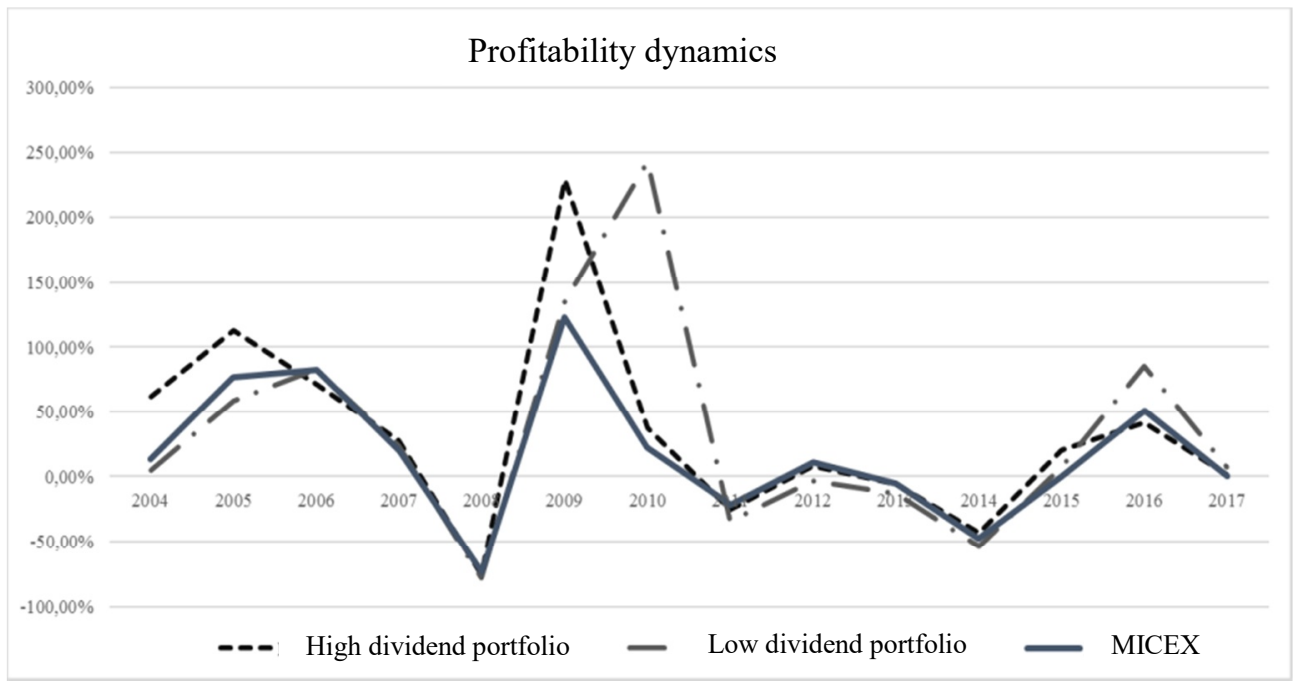

Fig. 1. Annual dynamics of portfolio returns in the Russian market.

Considering the risk adjustment, the dividend yields are still exceeding the MICEX index by three ratios. The higher rates are observed for the Top 5 strategy (the Sharpe ratio is 0.459 , the Sortino ratio is 1.462 , and the modified Sharpe ratio is 0.503 ), which may be due to the fact that the Top 5 included the companies inherent in sectors of strategic importance of the country, as well as well-established in the Russian market companies.

To estimate the ratios in the Fama-French three-factor model, a correlation matrix was drawn up in order to view the relationship between the calculated HML, SMB portfolios and the market portfolio adjusted to a risk-free rate. There is a weak correlation between the indicators, which makes it possible to estimate the ratios of the three-factor model without adjusting it for multicollinearity (Table 3 ).

Table 3. Correlation matrix (Source: Authors' calculations).

\begin{tabular}{|c|c|c|c|}
\hline & Rm - Rf & SMB & HML \\
\hline Rm - Rf & 1 & & \\
\hline SMB & 0.228 & 1 & \\
\hline HML & -0.135 & -0.472 & 1 \\
\hline
\end{tabular}

The excess profitability of a low-dividend portfolio turned out to be higher than the yield of the high-dividend and the Top 10 portfolios; the alpha ratio in the CAPM model was 0.137 , which is higher than all the others; according to the three-factor model, the highest alpha is observed in the Top 5 portfolio (0.169). The Russian market features the sensitivity to market risk in both models at a $1 \%$ level of significance. At the same time, the measure of sensitivity decreases to the market profitability as the dividend shares in the portfolio increase according to the Fama-French three-factor model (Table 4). 
Table 4. Estimation of ratios by the CAPM model and the Fama-French three-factor model (Source: Authors' calculations).

\begin{tabular}{|c|c|c|c|c|c|c|}
\hline \multirow[b]{2}{*}{ Portfolio } & \multicolumn{2}{|c|}{ CAPM model } & \multicolumn{4}{|c|}{ Fama-French three-factor model } \\
\hline & $\alpha$ & $\beta$ & $\alpha$ & $\beta$ & $\beta_{\mathrm{SMB}}$ & $\beta_{\mathrm{HML}}$ \\
\hline $\begin{array}{l}\text { High } \\
\text { dividend }\end{array}$ & $\begin{array}{l}0.09 \\
(0.077)\end{array}$ & $\begin{array}{l}1.335^{* * *} \\
(0.144)\end{array}$ & $\begin{array}{l}0.118 \\
(0.085)\end{array}$ & $\begin{array}{l}1.355^{* * *} \\
(0.164)\end{array}$ & $\begin{array}{l}-0.075 \\
(0.234)\end{array}$ & $\begin{array}{l}-0.136 \\
(0.286)\end{array}$ \\
\hline $\begin{array}{l}\text { Low } \\
\text { dividend }\end{array}$ & $\begin{array}{l}0.134 \\
(0.179)\end{array}$ & $\begin{array}{l}1.105^{* * *} \\
(0.336)\end{array}$ & $\begin{array}{l}0.027 \\
(0.036)\end{array}$ & $\begin{array}{l}0.873 \text { *** } \\
(0.069)\end{array}$ & $\begin{array}{l}0.621 * * * \\
(0.099)\end{array}$ & $\begin{array}{l}-0.292^{* * *} \\
(0.121)\end{array}$ \\
\hline Top 1 & $\begin{array}{l}0.071 \\
(0.068)\end{array}$ & $\begin{array}{l}1.278^{* * * *} \\
(0.127)\end{array}$ & $\begin{array}{l}0.18 \\
(0.141)\end{array}$ & $\begin{array}{l}1.532 * * * \\
(0.272)\end{array}$ & $\begin{array}{l}-0.299 \\
(0.389)\end{array}$ & $\begin{array}{l}-0.207 \\
(0.475)\end{array}$ \\
\hline Top 5 & $\begin{array}{l}0.121 \\
(0.104)\end{array}$ & $\begin{array}{l}1.466^{* * *} \\
(0.195)\end{array}$ & $\begin{array}{l}0.169 \\
(0.116)\end{array}$ & $\begin{array}{l}1.486^{* * *} \\
(0.224)\end{array}$ & $\begin{array}{l}0.039 \\
(0.319)\end{array}$ & $\begin{array}{l}0.078 \\
(0.389)\end{array}$ \\
\hline Top 10 & $\begin{array}{l}0.127 \\
(0.132)\end{array}$ & $\begin{array}{l}1.445^{* * *} \\
(0.248)\end{array}$ & $\begin{array}{l}0.109 \\
(0.073)\end{array}$ & $\begin{array}{l}1.27 * * * \\
(0.141)\end{array}$ & $\begin{array}{l}0.157 \\
(0.201)\end{array}$ & $\begin{array}{l}0.161 \\
(0.246)\end{array}$ \\
\hline
\end{tabular}

Note: $\mathrm{p}<0.1^{*}, \mathrm{p}<0.05^{* *}, \mathrm{p}<0.01^{* * *}$

Premium ratios for small capitalization and premium for the high multiplier of the market book value of shares in the low-dividend portfolio were also significant on the Russian market.

\subsection{Formation of high-dividend portfolios in the Indian market}

The sample for the Indian market included 54 companies from the BSESensex index; this index was taken as a benchmark. November was the preferred baseline month for portfolio rebalancing, and the yield values of the simulated portfolios will be calculated based on the values of quotes by the end of November. The dynamics of portfolio returns over 13 years is reflected in Table 5 .

Table 5. The profitability of portfolios and the BSESensex index in 2004-2017 (Source: Authors' calculations).

\begin{tabular}{|c|c|c|c|c|c|c|}
\hline & $\mathbf{1 0}$ & $\mathbf{5}$ & $\mathbf{1}$ & $\begin{array}{c}\text { High } \\
\text { dividend }\end{array}$ & $\begin{array}{c}\text { Low } \\
\text { dividend }\end{array}$ & BSE Sensex \\
\hline 2004 & $23.78 \%$ & $11.54 \%$ & $-5.07 \%$ & $26.62 \%$ & $36.97 \%$ & $27.10 \%$ \\
\hline 2005 & $46.26 \%$ & $51.37 \%$ & $81.81 \%$ & $38.39 \%$ & $36.66 \%$ & $36.77 \%$ \\
\hline 2006 & $39.43 \%$ & $37.51 \%$ & $37.94 \%$ & $45.77 \%$ & $63.90 \%$ & $60.41 \%$ \\
\hline 2007 & $30.45 \%$ & $46.23 \%$ & $15.57 \%$ & $38.92 \%$ & $72.19 \%$ & $59.51 \%$ \\
\hline 2008 & $-61.3 \%$ & $-60.29 \%$ & $-9.10 \%$ & $-58.96 \%$ & $-62.44 \%$ & $-62.57 \%$ \\
\hline 2009 & $191.1 \%$ & $261.11 \%$ & $416.37 \%$ & $174.73 \%$ & $96.59 \%$ & $98.31 \%$ \\
\hline 2010 & $21.31 \%$ & $6.42 \%$ & $3.17 \%$ & $28.77 \%$ & $-1.42 \%$ & $17.19 \%$ \\
\hline 2011 & $-14.4 \%$ & $-8.00 \%$ & $-10.79 \%$ & $-21.34 \%$ & $-38.36 \%$ & $-27.42 \%$ \\
\hline 2012 & $11.85 \%$ & $8.73 \%$ & $-12.34 \%$ & $15.48 \%$ & $11.95 \%$ & $15.24 \%$ \\
\hline 2013 & $-8.94 \%$ & $-22.36 \%$ & $-9.56 \%$ & $-14.66 \%$ & $-7.74 \%$ & $-6.51 \%$ \\
\hline 2014 & $43.55 \%$ & $41.70 \%$ & $31.01 \%$ & $37.80 \%$ & $36.76 \%$ & $38.42 \%$ \\
\hline 2015 & $-17.3 \%$ & $-21.88 \%$ & $-12.74 \%$ & $-20.42 \%$ & $-17.60 \%$ & $-14.70 \%$ \\
\hline 2016 & $19.71 \%$ & $35.55 \%$ & $147.20 \%$ & $21.66 \%$ & $-2.53 \%$ & $-1.23 \%$ \\
\hline 2017 & $28.75 \%$ & $23.77 \%$ & $-4.68 \%$ & $31.54 \%$ & $25.21 \%$ & $32.29 \%$ \\
\hline \hline $\begin{array}{l}\text { Average annual } \\
\text { return }\end{array}$ & $25.31 \%$ & $29.39 \%$ & $47.77 \%$ & $24.59 \%$ & $17.87 \%$ & $19.49 \%$ \\
\hline Sharp ratio & 0.452 & 0.398 & 0.414 & 0.465 & 0.41 & 0.478 \\
\hline Sortino ratio & 1.173 & 1.336 & 4.921 & 1.103 & 0.683 & 0.817 \\
\hline $\begin{array}{l}\text { Modified Sharp } \\
\text { Ratio }\end{array}$ & 0.492 & 0.443 & 0.47 & 0.5 & 0.41 & 0.472 \\
\hline
\end{tabular}




\begin{tabular}{|l|c|c|c|c|c|c|}
\hline $\begin{array}{l}\text { Standart } \\
\text { deviation }\end{array}$ & 0.56 & 0.738 & 1.154 & 0.529 & 0.436 & 0.408 \\
\hline Excess & 6.346 & 8.403 & 9.027 & 5.037 & -0.263 & 0.433 \\
\hline Assymetry & 1.912 & 2.544 & 2.902 & 1.558 & -0.007 & -0.113 \\
\hline
\end{tabular}

The excess return on dividend portfolios in relation to the market ranged from $5 \%$ to $28 \%$. The average annual yield of a low-dividend portfolio lost to the market portfolio for 13 years. After adjusting for risk, only the Top 10 and the high-dividend portfolios can be considered as super-profitable. The BSESensex index features the highest Sharpe ratio (0.478) in comparison with other portfolios, however, the Sortino ratio and the modified Sharpe ratio are higher for the Top 10 portfolio (1.173 and 0.492 , respectively); it is also should be noted that the market portfolio is inferior to all portfolios by the ratio. The highest volatility is for the portfolio formed by the Top 1 strategy, which is similar to the situation in the Russian market. The dynamics of profitability over 13 years is presented in Figure 2.

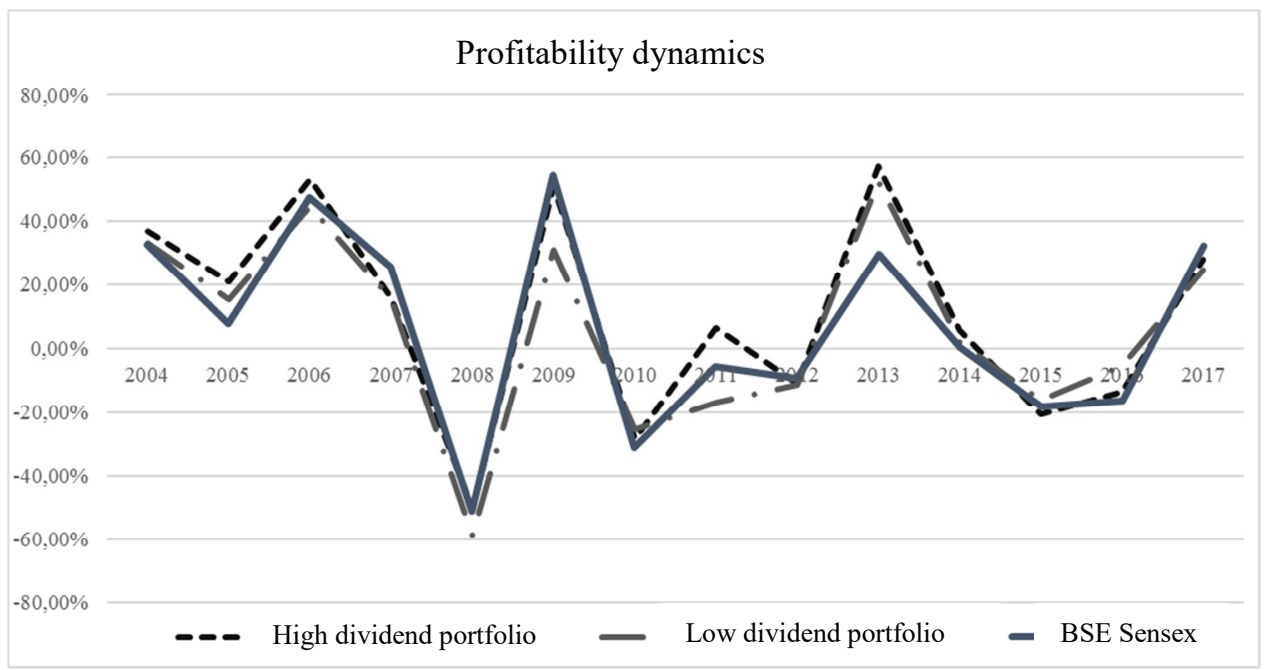

Fig. 2. Annual dynamics of portfolio returns in the Indian market.

In order to estimate the ratios in the Fama-French three-factor model, a correlation ratio was also found; the Table 5 presents the correlation matrix where the largest negative relationship is between the high multiplier premium and the market risk premium, however, the factor is $<0.5$ by absolute value, which allows to estimate the ratios of the three-factor model without multicollinearity adjustment (Table 6).

Table 6. Correlation matrix (Source: Authors' calculations).

\begin{tabular}{|c|c|c|c|}
\hline & Rm - Rf & SMB & HML \\
\hline Rm - Rf & 1 & & \\
\hline SMB & 0.371 & 1 & \\
\hline HML & -0.469 & -0.405 & 1 \\
\hline
\end{tabular}

The excess profitability of the Top 10 portfolio surpassed the yield of the high-dividend portfolio $(25.31 \%$ and $24.59 \%$ ), while the index profitability was only $19.49 \%$. In the Indian market, the CAPM beta models indices were significant at $1 \%$ level of significance for four portfolios and at 5\% level of significance for Top 1, which indicates the sensitivity of the return to market risk; the three-factor model has similar results except for the Top 1 portfolio, where the beta coefficient is not significant even by $10 \%$. The influence of the 
premium for the size of the company was significant at $1 \%$ significance level in four portfolios out of five, and the alpha ratio in the Fama-French model in the high-dividend portfolio was 0.56 and is significant at $5 \%$ level and 0.253 in the Top 1 portfolio at $10 \%$ significance level (Table 7).

Table 7. Estimation of ratios by the CAPM model and the Fama-French three-factor model (Source: Authors' calculations).

\begin{tabular}{|l|l|l|l|l|l|l|}
\hline & \multicolumn{2}{|c|}{ CAPM model } & \multicolumn{4}{c|}{ Fama-French three-factor model } \\
\hline Portfolio & $\alpha$ & $\beta$ & $\alpha$ & $\beta$ & $\beta_{S M B}$ & $\beta_{H M L}$ \\
\hline High & 0.016 & $1.182^{* * *}$ & $0.056^{* *}$ & $0.783^{* * *}$ & $0.815^{* * *}$ & -0.189 \\
dividend & $(0.068)$ & $(0.155)$ & $(0.023)$ & $(0.083)$ & $(0.136)$ & $(0.153)$ \\
\hline Low & -0.027 & $1.055^{* * *}$ & 0.007 & $1.046^{* * *}$ & -0.15 & -0.128 \\
dividend & $(0.023)$ & $(0.052)$ & $(0.026)$ & $(0.094)$ & $(0.153)$ & $(0.173)$ \\
\hline Top 1 & 0.154 & $1.659^{* *}$ & $0.253^{*}$ & -0.253 & $3.028^{* * *}$ & -1.356 \\
& $(0.29)$ & $(0.662)$ & $(0.12)$ & $(0.437)$ & $(0.715)$ & $(0.808)$ \\
\hline Top 5 & 0.006 & $1.477^{* * *}$ & 0.071 & $0.613^{* * *}$ & $1.384^{* * *}$ & -0.634 \\
& $(0.132)$ & $(0.302)$ & $(0.05)$ & $(0.181)$ & $(0.297)$ & $(0.335)$ \\
\hline Top 10 & 0.018 & $1.208^{* * *}$ & 0.055 & $0.778^{* * *}$ & $1.093^{* * *}$ & -0.063 \\
& $(0.083)$ & $(0.189)$ & $(0.032)$ & $(0.116)$ & $(0.189)$ & $(0.214)$ \\
\hline
\end{tabular}

Note: $\mathrm{p}<0.1^{*}, \mathrm{p}<0.05^{* *}, \mathrm{p}<0.01^{* * *}$

\subsection{Formation of high-dividend portfolios in the Spanish market}

In the Spanish market, 62 companies included in the IBEX35 index from July 30, 2003 to December 2016 were used in the study. The benchmark is the IBEX35 index.

Just as for India, November was chosen to berebalancingmonth as the most attractive for investment reasons. The results of covered portfolio returns are presented in Table 8 .

Table 8. The profitability of portfolios and the IBEX35 index in 2004-2017 (Source: Authors' calculations).

\begin{tabular}{|c|c|c|c|c|c|c|}
\hline & $\mathbf{1 0}$ & $\mathbf{5}$ & $\mathbf{1}$ & $\begin{array}{c}\text { High } \\
\text { dividend }\end{array}$ & $\begin{array}{c}\text { Low } \\
\text { dividend }\end{array}$ & TOPIX30 \\
\hline 2004 & $36.86 \%$ & $43.07 \%$ & $31.06 \%$ & $37.06 \%$ & $33.21 \%$ & $32.85 \%$ \\
\hline 2005 & $18.62 \%$ & $13.36 \%$ & $21.15 \%$ & $21.19 \%$ & $15.41 \%$ & $7.71 \%$ \\
\hline 2006 & $59.52 \%$ & $67.92 \%$ & $78.06 \%$ & $53.36 \%$ & $44.64 \%$ & $47.35 \%$ \\
\hline 2007 & $14.14 \%$ & $-1.04 \%$ & $18.38 \%$ & $15.99 \%$ & $15.59 \%$ & $25.75 \%$ \\
\hline 2008 & $-48.98 \%$ & $-49.24 \%$ & $-46.87 \%$ & $-50.12 \%$ & $-58.64 \%$ & $-50.94 \%$ \\
\hline 2009 & $58.53 \%$ & $59.37 \%$ & $99.78 \%$ & $51.06 \%$ & $31.08 \%$ & $54.48 \%$ \\
\hline 2010 & $-25.95 \%$ & $-27.78 \%$ & $-28.23 \%$ & $-28.40 \%$ & $-25.19 \%$ & $-31.18 \%$ \\
\hline 2011 & $8.06 \%$ & $-0.45 \%$ & $-11.65 \%$ & $6.55 \%$ & $-16.64 \%$ & $-5.56 \%$ \\
\hline 2012 & $-15.1 \%$ & $-3.82 \%$ & $-3.71 \%$ & $-10.81 \%$ & $-11.21 \%$ & $-9.29 \%$ \\
\hline 2013 & $45.58 \%$ & $54.87 \%$ & $25.61 \%$ & $57.30 \%$ & $52.69 \%$ & $29.76 \%$ \\
\hline 2014 & $15.94 \%$ & $13.34 \%$ & $10.45 \%$ & $5.74 \%$ & $2.24 \%$ & $0.31 \%$ \\
\hline 2015 & $-22.35 \%$ & $-36.58 \%$ & $-39.82 \%$ & $-20.39 \%$ & $-15.99 \%$ & $-18.18 \%$ \\
\hline 2016 & $-6.82 \%$ & $-6.92 \%$ & $-4.60 \%$ & $-13.28 \%$ & $-5.11 \%$ & $-16.18 \%$ \\
\hline 2017 & $22.63 \%$ & $20.68 \%$ & $23.23 \%$ & $28.22 \%$ & $24.59 \%$ & $32.15 \%$ \\
\hline \hline $\begin{array}{l}\text { Average annual } \\
\text { return }\end{array}$ & $11.48 \%$ & $10.48 \%$ & $12.34 \%$ & $10.96 \%$ & $6.19 \%$ & $7.07 \%$ \\
\hline Sharp ratio & 0.352 & 0.291 & 0.302 & 0.334 & 0.203 & 0.228 \\
\hline Sortino ratio & 0.465 & 0.380 & 0.465 & 0.397 & 0.16 & 0.213 \\
\hline $\begin{array}{l}\text { Modified Sharp } \\
\text { Ratio }\end{array}$ & 0.350 & 0.293 & 0.312 & 0.331 & 0.200 & 0.227 \\
\hline Standart deviation & 0.326 & 0.360 & 0.409 & 0.329 & 0.306 & 0.310 \\
\hline
\end{tabular}




\begin{tabular}{|l|c|c|c|c|c|c|}
\hline Excess & -0.657 & -0.813 & 0.550 & -0.811 & -0.035 & -0.777 \\
\hline Assymetry & -0.167 & 0.087 & 0.689 & -0.203 & -0.417 & -0.191 \\
\hline
\end{tabular}

The low-dividend portfolio was the least profitable (6.19\%) and its average annual yield was lower than the benchmark $(7.07 \%)$, while the dividend portfolios surpassed the IBEX35 index even with risk adjustments. Among the risk-adjusted portfolios, the most attractive one becomes a portfolio drawn up by the classic Top 10 strategy. Figure 13 clearly shows that a high-dividend portfolio exceeds the benchmark for 13 years.

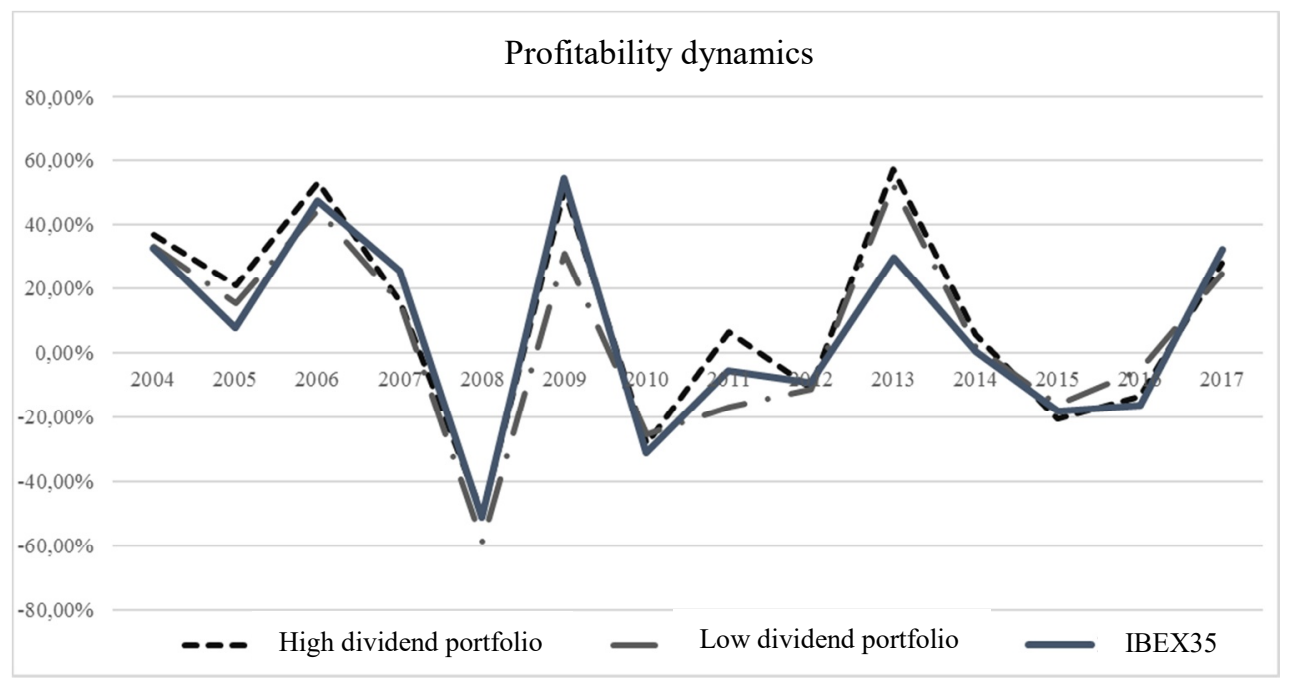

Fig. 3. Annual dynamics of portfolio returns in the Spanish market.

Just as in previous countries, there is a weak correlation between the indicators; therefore, the ratios of the three-factor model will be estimated without adjusting for multicollinearity (Table 9).

Table 9. Correlation matrix (Source: Authors' calculations).

\begin{tabular}{|c|c|c|c|}
\hline & Rm - Rf & SMB & HML \\
\hline Rm - Rf & 1 & & \\
\hline SMB & 0.2073 & 1 & \\
\hline HML & -0.4675 & -0.3884 & 1 \\
\hline
\end{tabular}

The alpha coefficient estimation for the portfolio by the classic Dogs of the Dow strategy in the CAPM model was 0.044; the next highest value is observed for the highdividend portfolio. The Spanish market features the sensitivity to market risk, both by the CAPM model and by the three-factor one. At the same time, the measure of sensitivity increases to the market profitability as the dividend shares in the portfolio increase according to the Fama-French three-factor model (Table 10). 
Table 10. Estimation of ratios by the CAPM model and the Fama-French three-factor model (Source: Authors' calculations).

\begin{tabular}{|c|c|c|c|c|c|c|}
\hline & \multicolumn{2}{|c|}{ CAPM model } & \multicolumn{4}{c|}{ Fama-French three-factor model } \\
\hline Portfolio & $\alpha$ & $\beta$ & $\alpha$ & $\beta$ & $\beta_{S M B}$ & $\beta_{H M L}$ \\
\hline High & 0.038 & $1.017^{* * *}$ & $0.074^{* * *}$ & $0.914^{* * *}$ & $0.383^{* *}$ & $-0.279^{*}$ \\
dividend & $(0.026)$ & $(0.086)$ & $(0.017)$ & $(0.069)$ & $(0.13)$ & $(0.146)$ \\
\hline Low & -0.003 & $0.920^{* * *}$ & 0.029 & $0.847^{* * *}$ & $0.415^{* *}$ & -0.157 \\
dividend & $(0.031)$ & $(0.102)$ & $(0.027)$ & $(0.109)$ & $(0.204)$ & $(0.229)$ \\
\hline Top 1 & 0.037 & $1.219^{* * *}$ & $0.08^{* * *}$ & $0.895^{* * *}$ & $0.344^{* *}$ & $-0.322^{* *}$ \\
& $(0.044)$ & $(0.145)$ & $(0.018)$ & $(0.072)$ & $(0.135)$ & $(0.152)$ \\
\hline Top 5 & 0.029 & $1.071^{* * *}$ & $0.069^{* *}$ & $0.957^{* * *}$ & $0.656^{* *}$ & -0.226 \\
& $(0.04)$ & $(0.129)$ & $(0.028)$ & $(0.112)$ & $(0.21)$ & $(0.237)$ \\
\hline Top 10 & 0.044 & $1.007^{* * *}$ & 0.078 & $1.155^{* * *}$ & 0.379 & -0.147 \\
& $(0.026)$ & $(0.086)$ & $(0.045)$ & $(0.182)$ & $(0.34)$ & $(0.383)$ \\
\hline
\end{tabular}

Note: $\mathrm{p}<0.1^{*}, \mathrm{p}<0.05^{* *}, \mathrm{p}<0.01^{* * *}$

Three of five portfolios had significant alpha ratios in the Fama-French three-factor model, four portfolios had a significant influence of the small capitalization premium to profitability; the ratio of the variable HML was negative for all the portfolios, but only for two ones it was significant. The negative sign in front of the sensitivity ratio can be explained by the fact that almost over the whole period under review, the HML indicator was negative.

\subsection{Formation of high-dividend portfolios in the Japanese market}

The sample for the Japanese market included 48 companies that were included in the TOPIX30 index from July 30, 2003 to December 2016. The TOPIX30 index was chosen as a benchmark, while the baseline month was the traditional month of rebalancing (December). The results of portfolio returns for the Japanese market are presented in Table 11.

Table 11. Return on portfolios and TOPIX30 index in 2004-2017 (Source: Authors' calculations).

\begin{tabular}{|c|c|c|c|c|c|c|}
\hline & $\mathbf{1 0}$ & $\mathbf{5}$ & $\mathbf{1}$ & $\begin{array}{c}\text { High } \\
\text { dividend }\end{array}$ & $\begin{array}{c}\text { Low } \\
\text { dividend }\end{array}$ & TOPIX30 \\
\hline 2004 & $17.7 \%$ & $17.3 \%$ & $12.2 \%$ & $14.93 \%$ & $15.03 \%$ & $10.19 \%$ \\
\hline 2005 & $9.1 \%$ & $3.8 \%$ & $-1.1 \%$ & $9.46 \%$ & $1.47 \%$ & $16.87 \%$ \\
\hline 2006 & $23.4 \%$ & $28.7 \%$ & $33.1 \%$ & $24.57 \%$ & $-0.64 \%$ & $6.53 \%$ \\
\hline 2007 & $0.5 \%$ & $2.8 \%$ & $-9.8 \%$ & $0.79 \%$ & $-10.67 \%$ & $-6.87 \%$ \\
\hline 2008 & $-35.8 \%$ & $-42.8 \%$ & $-68.0 \%$ & $-31.90 \%$ & $-36.60 \%$ & $-33.92 \%$ \\
\hline 2009 & $35.6 \%$ & $52.4 \%$ & $146.7 \%$ & $25.48 \%$ & $-3.85 \%$ & $0.88 \%$ \\
\hline 2010 & $15.0 \%$ & $11.9 \%$ & $22.8 \%$ & $9.19 \%$ & $10.77 \%$ & $9.63 \%$ \\
\hline 2011 & $-23.5 \%$ & $-16.1 \%$ & $-28.3 \%$ & $-17.63 \%$ & $-21.35 \%$ & $-21.26 \%$ \\
\hline 2012 & $2.0 \%$ & $13.4 \%$ & $33.9 \%$ & $10.42 \%$ & $6.66 \%$ & $10.34 \%$ \\
\hline 2013 & $15.2 \%$ & $14.3 \%$ & $3.1 \%$ & $23.83 \%$ & $29.87 \%$ & $25.10 \%$ \\
\hline 2014 & $-6.1 \%$ & $-4.6 \%$ & $1.5 \%$ & $-6.24 \%$ & $-7.95 \%$ & $-10.35 \%$ \\
\hline 2015 & $11.2 \%$ & $12.8 \%$ & $20.7 \%$ & $7.38 \%$ & $3.19 \%$ & $6.27 \%$ \\
\hline 2016 & $-3.1 \%$ & $-1.6 \%$ & $14.4 \%$ & $-1.35 \%$ & $0.60 \%$ & $-2.04 \%$ \\
\hline 2017 & $12.6 \%$ & $17.6 \%$ & $32.2 \%$ & $15.63 \%$ & $20.75 \%$ & $16.53 \%$ \\
\hline \hline $\begin{array}{l}\text { Average annual } \\
\text { return }\end{array}$ & $5.27 \%$ & $7.85 \%$ & $15.26 \%$ & $6.04 \%$ & $0.52 \%$ & $1.99 \%$ \\
\hline Sharp ratio & 0.285 & 0.361 & 0.326 & 0.369 & 0.031 & 0.126 \\
\hline
\end{tabular}




\begin{tabular}{|l|c|c|c|c|c|c|}
\hline Sortino ratio & 0.17 & 0.35 & 0.576 & 0.261 & -0.185 & -0.081 \\
\hline $\begin{array}{l}\text { Modified Sharp } \\
\text { Ratio }\end{array}$ & 0.274 & 0.348 & 0.344 & 0.344 & 0.0307 & 0.123 \\
\hline $\begin{array}{l}\text { Standart } \\
\text { deviation }\end{array}$ & 0.185 & 0.217 & 0.467 & 0.164 & 0.169 & 0.159 \\
\hline Excess & 0.9191 & 2.237 & 5.168 & 0.911 & 0.85 & 0.731 \\
\hline Assymetry & -0.809 & -0.405 & 1.412 & -1.006 & -0.481 & -0.92 \\
\hline
\end{tabular}

The excess profitability of the high-dividend portfolio was $6.04 \%$, which is three times more than the TOPIX30 profitability for the same period. In general, all the dividend strategies beat the market with a compelling advantage; the low-dividend portfolio turned out to be the least profitable and inferior more than $1 \%$ of the profitability to the market portfolio. After the risk adjustment, the dividend strategies also turn out to be investmentattractive; the highest Sharpe ratio is 0.369 for the high-dividend portfolio, the Sortino ratio is 0.576 for the Top 1 and the modified Sharpe ratio is 0.348 for Top 5. The profitability by the low-dividend portfolio is more than 10 times lower than by the high-dividend portfolio. Figure 14 illustrates the dynamics over 13 years.

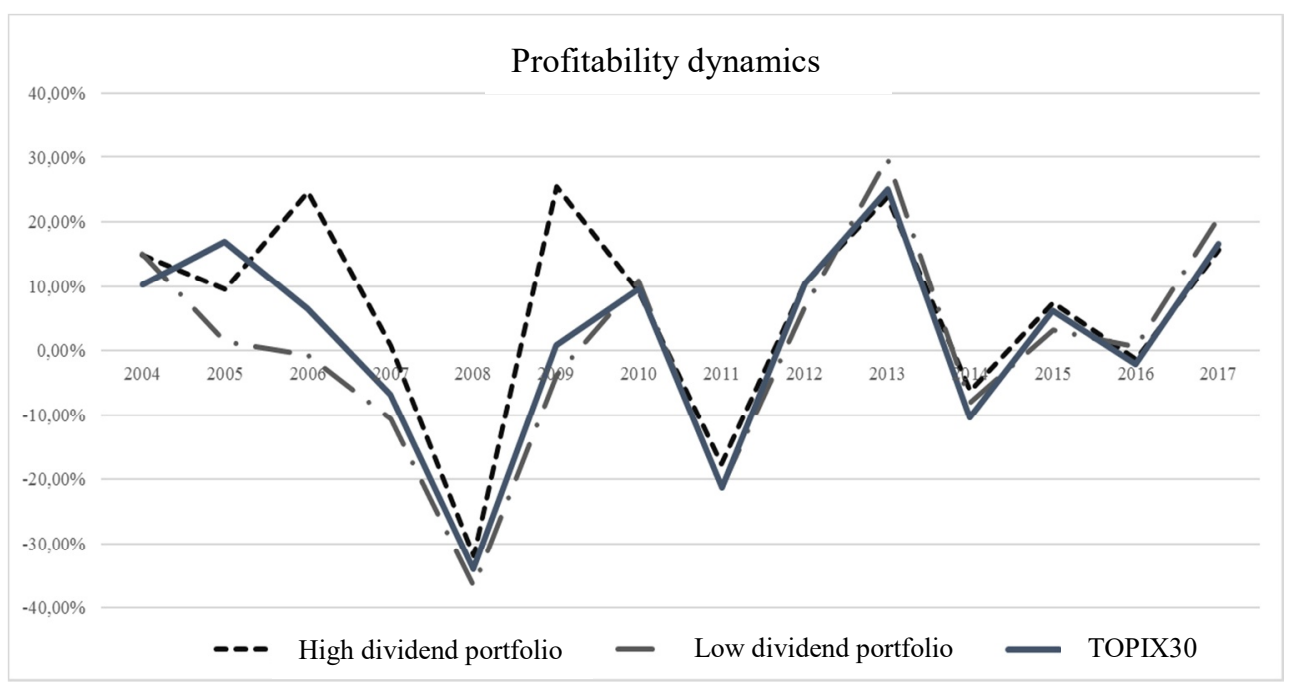

Fig. 4. Annual dynamics of portfolio returns in the Japanese market.

The data for Japan do not differ from previous countries in the matter of correlation of indicators for estimating the three-factor model ratios. Since there is a weak correlation, the multicollinearity problem will be considered settled (Table 12).

Table 12. Correlation matrix (Source: Authors' calculations).

\begin{tabular}{|c|c|c|c|}
\hline & Rm - Rf & SMB & HML \\
\hline Rm - Rf & 1 & & \\
\hline SMB & -0.01232 & 1 & \\
\hline HML & -0.40622 & -0.0792 & 1 \\
\hline
\end{tabular}

The assessment of the alpha ratio for the high-dividend portfolio is 0.42 and is significant at $10 \%$ significance level according to the CAPM model, which is less than the ratio of the Top 1 portfolio and the Top 5 portfolio. According to the three-factor model, the influence of the market risk premium of the high-dividend portfolio was also significant. The Japanese market features sensitivity to market risk in both the CAPM model and the three-factor risk for all portfolios except for Top 1.It should be noted that no 
indicator was significant for the Top 1 portfolio in two models. If you do not take into account the low-dividend portfolio, the measure of sensitivity decreases to the market profitability as the dividend shares in the portfolio increase according to the Fama-French three-factor model and CAPM model (Table 13).

Table 13. Estimation of ratios by the CAPM model and the Fama-French three-factor model (Source: Authors' calculations).

\begin{tabular}{|l|l|l|l|l|l|l|}
\hline & \multicolumn{2}{|c|}{ CAPM model } & \multicolumn{4}{c|}{ Fama-French three-factor model } \\
\hline Portfolio & $\alpha$ & $\beta$ & $\alpha$ & $\beta$ & $\beta_{S M B}$ & $\beta_{H M L}$ \\
\hline High dividend & $0.042^{*}$ & $0.898^{* * *}$ & $0.064^{* *}$ & $0.924^{* * *}$ & 0.304 & 0.102 \\
& $(0.023)$ & $(0.146)$ & $(0.026)$ & $(0.175)$ & $(0.236)$ & $(0.333)$ \\
\hline Low dividend & -0.015 & $1.003^{* * *}$ & 0.006 & $1.014^{* * *}$ & $0.302^{* *}$ & -0.105 \\
& $(0.016)$ & $(0.101)$ & $(0.013)$ & $(0.088)$ & $(0.118)$ & $(0.167)$ \\
\hline Top 1 & 0.127 & 1.301 & 0.148 & 1.488 & 1.271 & 0.82 \\
& $(0.118)$ & $(0.762)$ & $(0.129)$ & $(0.883)$ & $(1.186)$ & $(1.679)$ \\
\hline Top 5 & 0.060 & $0.934^{* * *}$ & 0.078 & $0.964^{* *}$ & 0.473 & 0.136 \\
& $(0.045)$ & $(0.289)$ & $(0.05)$ & $(0.344)$ & $(0.462)$ & $(0.654)$ \\
\hline Top 10 & 0.035 & $0.907^{* * *}$ & 0.059 & $0.943^{* * *}$ & 0.249 & 0.193 \\
& $(0.032)$ & $(0.211)$ & $(0.038)$ & $(0.262)$ & $(0.351)$ & $(0.497)$ \\
\hline
\end{tabular}

It should be noted, that in the Japanese market, the impact of the small capitalization premium on the yield of the low-dividend portfolio turned out to be significant at a $5 \%$ level of significance.

\subsection{Analysis of modified strategies based on pooled data}

In this part of the paper, data on companies included in the country index by the end of December of each year were combined. As the baseline month for rebalancing the classic version was chosen(December). Seven portfolios were formed on the most well-known modifications of the dividend strategy, namely High Yield 10 (Top 10), High Yield 5 (Top 5), High Yield 1 (Top 1), Beating the Dow (BTD), Foolish Four (FF) and Foolish Two (FT), and Penultimate profit prospect (PPP).

The first one will be the results of the portfolios formed on the pooled data of the Indian and Russian markets. The average annual returns are shown in Table 14.

Table 14. Portfolio returns in developing markets (Source: Authors' calculations).

\begin{tabular}{|l|l|l|l|l|l|l|l|}
\hline & 10 & 5 & 1 & BTD & PPP & FF & FT \\
\hline 2004 & $16.71 \%$ & $3.15 \%$ & $5.92 \%$ & $21.12 \%$ & $39.46 \%$ & $18.57 \%$ & $35.88 \%$ \\
\hline 2005 & $78.61 \%$ & $119.02 \%$ & $192.42 \%$ & $94.54 \%$ & $188.79 \%$ & $70.07 \%$ & $83.84 \%$ \\
\hline 2006 & $32.84 \%$ & $44.48 \%$ & $21.55 \%$ & $41.78 \%$ & $25.35 \%$ & $41.95 \%$ & $61.04 \%$ \\
\hline 2007 & $43.75 \%$ & $30.52 \%$ & $36.93 \%$ & $37.31 \%$ & $105.13 \%$ & $57.60 \%$ & $71.03 \%$ \\
\hline 2008 & $-67.82 \%$ & $-61.25 \%$ & $-67.22 \%$ & $-60.98 \%$ & $-85.44 \%$ & $-77.73 \%$ & $-80.55 \%$ \\
\hline 2009 & $236.35 \%$ & $328.80 \%$ & $247.90 \%$ & $316.99 \%$ & $342.02 \%$ & $334.27 \%$ & $242.37 \%$ \\
\hline 2010 & $30.37 \%$ & $15.92 \%$ & $16.16 \%$ & $29.12 \%$ & $6.66 \%$ & $15.85 \%$ & $40.15 \%$ \\
\hline 2011 & $-13.03 \%$ & $-11.61 \%$ & $-0.90 \%$ & $3.94 \%$ & $-2.69 \%$ & $5.15 \%$ & $4.00 \%$ \\
\hline 2012 & $14.57 \%$ & $6.00 \%$ & $41.66 \%$ & $15.37 \%$ & $2.80 \%$ & $12.22 \%$ & $-17.93 \%$ \\
\hline 2013 & $2.55 \%$ & $-7.59 \%$ & $-72.24 \%$ & $7.07 \%$ & $72.96 \%$ & $3.67 \%$ & $55.03 \%$ \\
\hline 2014 & $-36.16 \%$ & $-26.15 \%$ & $-76.57 \%$ & $-26.63 \%$ & $-45.05 \%$ & $-21.01 \%$ & $-17.09 \%$ \\
\hline 2015 & $17.81 \%$ & $36.50 \%$ & $48.16 \%$ & $19.16 \%$ & $23.32 \%$ & $21.19 \%$ & $9.82 \%$ \\
\hline 2016 & $50.84 \%$ & $44.05 \%$ & $71.71 \%$ & $46.19 \%$ & $-13.72 \%$ & $55.81 \%$ & $52.40 \%$ \\
\hline 2017 & $4.47 \%$ & $2.39 \%$ & $-6.63 \%$ & $-2.37 \%$ & $-6.63 \%$ & $-6.10 \%$ & $-5.93 \%$ \\
\hline $\begin{array}{l}\text { Average annual } \\
\text { return }\end{array}$ & $29.42 \%$ & $37.44 \%$ & $32.77 \%$ & $38.76 \%$ & $46.64 \%$ & $37.97 \%$ & $38.15 \%$ \\
\hline
\end{tabular}


Large returns were shown by portfolios that used the share price as an additional filter. A $46.64 \%$ excess return is observed in a portfolio consisting of one share with the second lowest price among ten most dividend shares; a portfolio with Foolish Two and Beating the Dow were also in the group of the most profitable portfolios, $38.76 \%$ and $38.15 \%$, respectively. According to the data obtained, one can conclude that developing markets are inherent in price shares, that is, there is a potential for growth and development of the company in future, and therefore the excess returns are traced. All seven strategies beat the high-dividend portfolio profitability in the Indian market and fivein the Russian one. In general, all the portfolios have showed returns of more than $29 \%$ in 13 years, while at the same time the dividend portfolios in the Indian market show returns from $24 \%$ and from $30 \%$ in the Russian one. Also, the highest possible profitability reaches $38 \%$ in the Russian market and $47 \%$ in the Indian market.

A similar analysis was carried out with companies in the Spanish and Japanese markets. The obtained results are shown in Table 15.

Table 15. Portfolio returns in developed markets (Source: Authors' calculations).

\begin{tabular}{|c|c|c|c|c|c|c|c|}
\hline & 10 & 5 & 1 & BTD & PPP & FF & FT \\
\hline 2004 & $31.60 \%$ & $33.99 \%$ & $22.13 \%$ & $27.94 \%$ & $36.73 \%$ & $27.79 \%$ & $33.21 \%$ \\
\hline 2005 & $12.32 \%$ & $9.65 \%$ & $-0.70 \%$ & $21.46 \%$ & $7.83 \%$ & $23.70 \%$ & $23.14 \%$ \\
\hline 2006 & $54.57 \%$ & $43.88 \%$ & $79.72 \%$ & $51.42 \%$ & $41.34 \%$ & $49.31 \%$ & $60.53 \%$ \\
\hline 2007 & $8.34 \%$ & $-4.42 \%$ & $12.16 \%$ & $3.26 \%$ & $15.64 \%$ & $-5.65 \%$ & $3.23 \%$ \\
\hline 2008 & $-38.75 \%$ & $-35.30 \%$ & $-24.62 \%$ & $-41.63 \%$ & $-53.10 \%$ & $-46.19 \%$ & $-36.62 \%$ \\
\hline 2009 & $52.95 \%$ & $63.45 \%$ & $96.16 \%$ & $77.26 \%$ & $96.16 \%$ & $59.89 \%$ & $86.49 \%$ \\
\hline 2010 & $-8.40 \%$ & $-14.36 \%$ & $-24.70 \%$ & $-10.06 \%$ & $-27.52 \%$ & $-13.93 \%$ & $-7.30 \%$ \\
\hline 2011 & $-5.96 \%$ & $-11.79 \%$ & $-23.65 \%$ & $-5.24 \%$ & $11.41 \%$ & $-10.16 \%$ & $-15.77 \%$ \\
\hline 2012 & $-2.12 \%$ & $1.96 \%$ & $7.71 \%$ & $8.47 \%$ & $16.32 \%$ & $12.54 \%$ & $16.98 \%$ \\
\hline 2013 & $40.00 \%$ & $51.79 \%$ & $20.99 \%$ & $45.14 \%$ & $19.88 \%$ & $41.50 \%$ & $21.14 \%$ \\
\hline 2014 & $8.05 \%$ & $7.77 \%$ & $4.73 \%$ & $11.28 \%$ & $11.13 \%$ & $12.75 \%$ & $6.72 \%$ \\
\hline 2015 & $-24.07 \%$ & $-35.11 \%$ & $-38.70 \%$ & $-34.00 \%$ & $-26.21 \%$ & $-19.89 \%$ & $-9.76 \%$ \\
\hline 2016 & $6.71 \%$ & $9.33 \%$ & $-0.18 \%$ & $18.46 \%$ & $-2.87 \%$ & $17.72 \%$ & $1.77 \%$ \\
\hline 2017 & $21.98 \%$ & $11.96 \%$ & $-26.85 \%$ & $32.91 \%$ & $28.48 \%$ & $30.80 \%$ & $16.80 \%$ \\
\hline $\begin{array}{c}\text { Average } \\
\text { annual } \\
\text { return }\end{array}$ & $11.23 \%$ & $9.49 \%$ & $7.44 \%$ & $14.76 \%$ & $12.51 \%$ & $12.87 \%$ & $14.32 \%$ \\
\hline
\end{tabular}

The most effective strategy in developed markets is Beating the Dow; it brought a profitability of $14.76 \%$. The next one by the performance of the portfolio is the Foolish Two strategy of $14.32 \%$. The portfolios formed according to the classic modifications are inferior to the same modifications in the Spanish market, however, they beat the portfolios in the Japanese market, except for the Top 1 (15.26\%). The BTD, PPP, FT and FF dividend strategies have exceeded the profitability of a high-dividend portfolio in each studied country separately.

Thus, the markets of the developing countries are the most attractive among the considered markets. The profitability of dividend portfolios on the Indian and Russian markets significantly exceeds the profitability of similar portfolios on the Japanese and Spanish markets, even after the adjusting for risk; the situation is similar to the pooled data: portfolios on the developing markets show excess returns several times higher than on the developed ones. The measure of the portfolio returns sensitivity to market risk is higher for the developing countries. 


\section{Conclusion}

According to the results of the study, the hypothesis about the presence of superprofitability of high-dividend strategies against the benchmark and low-dividend strategies has been confirmed in all the considered markets for 13 years except for Russia, where the profitability of low-dividend portfolio turned out to be higher than the profitability of highdividend portfolio. After the risk adjustment, all the dividend portfolios also beat the market portfolio and the low-dividend portfolio in Russia, Spain and Japan. In all markets, a measure of the portfolio sensitivity to market risk was found; the assessment of the alpha ratio by the CAPM model and the Fama-French three-factor model is positive for dividend portfolios in all four markets.

However, the study features several limitations. In the first place, the capitalizationweighted portfolios were not formed to compare the profitability with equally weighted portfolios; in the second place, when calculating the portfolio returns, the transaction costs associated with taxes, commission and currency conversion were not taken into account;in the third place, the dividends from portfolio performance were also neither taken into account, nor capitalized; and in the fourth place, the study period includes crisis years, which could have affected excess returns. In addition, only four countries were considered when testing modified strategies to obtain more accurate results.

The results of this paper can be used as a recommendation for investment in the considered markets, as well as for further research on the excess return of dividend strategies.

\section{References}

1. J. Slatter, Wall Street Journal, 1 (1988)

2. M. O'Higgins, J. Downes, Beating the Dow (Harper Collins, 1990)

3. G. McQueen, K. Shields, S.R. Thorley, Financial Analysts Journal 4, 66-72 (1997)

4. A. Cordeiro, Online magazine the wall street journal (2006) https://www.wsj.com/articles/SB115759086240955899?mod=djemITP

5. G. Morgan, S. Thomas, Journal of banking and finance 22, 405-423 (2009)

6. S. Visscher, G. Filbeck, Financial Analysts Journal 1, 99-106 (2003)

7. O.A.P. Gwilym, J. Seaton, S.H. Thomas, The Journal of Investing 4, 69-74 (2005)

8. L. Alles, Y.T. Shen, The Finsia Journal of Applied Finance 3, 30-38 (2008)

9. S. Visscher, G. Filbeck, Financial Analysts Journal 1, 99-106 (2003)

10. J. Brzeszczyński, J. Gajdka, International Advances in Economic Research 3, 285-300 (2007)

11. R. Eemeli, V. Sami, The European Journal of Finance 5-6, 451-469 (2011)

12. M. Qiu, Y. Song, M. Hasama, International journal of innovative computing, information and control 9, 3677-3684 (2013)

13. C. Wang, J.E. Larsen, M.F. Ainina, M.L. Akhbari, N. Gressis, International Journal of Business and Social Science 18, 70-80 (2011)

14. A.L.C. Da Silva, International Review of Financial Analysis 2, 187-199 (2003)

15. P. Keating, Online cnn money, archive, http://money.cnn.com/

16. E.F. Fama, The journal of finance 2, 383-417 (1970)

17. E.F. Fama, K.R. French, Journal of financial economics 1, 3-56 (1993) 
18. E.F. Fama, K.R. French, Journal of financial economics 1, 3-25 (1988)

19. E.F. Fama, K.R. French, The journal of finance 6, 1975-1999 (1998)

20. D.L. Domian, D.A. Louton, C.E. Mossman, Financial Services Review 3, 145-159 (1998)

21. M. Hirschey, Financial Review 2, 1-16 (2000)

22. C. Sahu, Vikalpa 1, 65-72 (2001)

23. J.G. Jeong, Y. Lee, S. Mukherji, The journal of wealth management, 95-103 (2009)

24. K.E. Kuzmichev, Efficiency of the formation of portfolios of high dividend stocks in the Russian stock market (2012)

25. T.T.L. Chong, K.K. Luk, Applied Economics Letters 12, 1173-1175 (2010)

26. G. McQueen, K. Shields, S.R. Thorley, Financial Analysts Journal 4, 66-72 (1997)

27. B. Bauer, T. Gardner, The Foolish Four: How to crush your mutual funds in 15 minutes a year (The Motley Fool, Virginia, 1999)

28. H. Wolmarans, Investment Management and Financial Innovations 3, 40-50 (2004)

29. M.A. Halperin, T.V. Teplova, The Economic Journal of the Higher School of Economics 2, 1-38 (2012)

30. N.I. Berzon, D.I. Doroshin, Finance and credit 14, 21-33 (2012)

31. L. Favre, J.A. Galeano, Journal of Alternative Investments 2, 21-25 (2002) 